\title{
Article \\ Electropolymerised pH Insensitive Salicylic Acid Reference Systems: Utilization in a Novel pH Sensor for Food and Environmental Monitoring
}

\author{
Monica Miranda Mugica (D), Kay Louise McGuinness and Nathan Scott Lawrence*
}

Citation: Miranda Mugica, M.; McGuinness, K.L.; Lawrence, N.S Electropolymerised $\mathrm{pH}$ Insensitive Salicylic Acid Reference Systems: Utilization in a Novel pH Sensor for Food and Environmental Monitoring Sensors 2022, 22, 555. https:// doi.org/10.3390/s22020555

Academic Editor: Paolo Ugo

Received: 7 December 2021

Accepted: 8 January 2022

Published: 11 January 2022

Publisher's Note: MDPI stays neutral with regard to jurisdictional claims in published maps and institutional affiliations.

Copyright: (C) 2022 by the authors. Licensee MDPI, Basel, Switzerland. This article is an open access article distributed under the terms and conditions of the Creative Commons Attribution (CC BY) license (https:// creativecommons.org/licenses/by/ $4.0 /)$.
ANB Sensors Ltd., 4 Penn Farm, Haslingfield, Cambridge CB23 1JZ, UK; mmugica@anbsensors.com (M.M.M.); kmcguinness@anbsensors.com (K.L.M.)

* Correspondence: nlawrence@anbsensors.com

\begin{abstract}
This work summarizes the electrochemical response of a salicylic acid-based carbon electrode for use as a novel solid-state reference electrode in a redox-based $\mathrm{pH}$ sensor. This novel reference produces a $\mathrm{pH}$ insensitive response over a range of $\mathrm{pH}$ 3-10 in solutions with low buffer concentrations, different compositions, conductivities, and ionic strengths is produced. The $\mathrm{pH}$ of the local environment is shown to be determined by the chemistry and the electrochemical response of the redox active species on the surface of the electrode; the local $\mathrm{pH}$ can be controlled by the electropolymerized salicylic acid moieties due to the acid concentration on the surface, avoiding any perturbation in environmental $\mathrm{pH}$ and leading to a stable novel reference system. Sensitivities of $-7.1 \mathrm{mV} / \mathrm{pH}$ unit, $-2.4 \mathrm{mV} / \mathrm{pH}$ unit, $-0.2 \mathrm{mV} / \mathrm{pH}$ unit, and $2.5 \mathrm{mV} / \mathrm{pH}$ units were obtained for different food medias, hydroponic solution, seawater, and cell-culture media, respectively, confirming its ability to control the local $\mathrm{pH}$ of the electrode. This reference system is paired with a new $\mathrm{pH}$ sensing element based on electropolymerized flavanone to provide a calibration free, $\mathrm{pH}$ sensitive sensor to effectively and accurately measure the $\mathrm{pH}$ of various media with high viscosity, low conductivity, low /high buffer concentration or cell-culture environment, presenting a maximum error of $+/-0.03$ $\mathrm{pH}$ units.
\end{abstract}

Keywords: square wave voltammetry; salicylic acid; reference electrode

\section{Introduction}

The monitoring of $\mathrm{pH}$ is extremely important in many industries, such as pharmaceutical, food, agricultural and environmental. This is because a number of chemical processes are dependent on the hydrogen ion concentrations [1-5]. It is the most common analytical measurement in industrial processing, and it plays a very important role in the food processing industry in order to ensure reliable product quality and consistent, well-defined properties which meet regulatory requirements to avoid causing health problems for consumers [6]. Indeed, regulatory compliance is not the only reason why $\mathrm{pH}$ is important. The $\mathrm{pH}$ of the media impacts food characteristics such as texture, taste, aroma, and others. Effective monitoring of $\mathrm{pH}$ in the food industry begins with testing raw materials and continues throughout production to the finished product. Acidic food has a natural $\mathrm{pH}$ of 4.6 or below. When acid is added to lower the finished $\mathrm{pH}$ to below 4.6, these foods are known as 'acidified foods', which include canned goods, salsas, sauces, and fruits, among others. In the production of these, a $\mathrm{pH}$ higher than 4.6 will end in an environment that encourages the growth of unfavorable bacteria that can cause illness [7].

Determining best practices for measuring $\mathrm{pH}$ can be a challenge, and despite its importance, very few new technologies have entered the market, which has a heavy reliance on the electrochemical glass $\mathrm{pH}$ probe. A review of the literature shows the glass $\mathrm{pH}$ electrode is still used in most applications because the glass bulb is reliable, easy to calibrate, sensitive to $\mathrm{pH}$ and provides quick real time measurements. However, even 
though it is easily calibrated, the necessity for calibration due to a drift in the reference electrode means it has high operational costs due to the number of man hours involved in the process [8]. The drift is caused by changes in the environment of the reference electrode chamber, impacting the potential of the $\mathrm{Ag} / \mathrm{AgCl}$ redox couple and therefore leading to an inaccurate $\mathrm{pH}$ measurement $[9,10]$. Further issues arise when trying to accurately measure $\mathrm{pH}$ in foods with high viscosity. Because of the limited interaction between the aqueous electrolyte and the viscous sample, there are a lot of inconsistencies in the reading and a longer response time.

Glass electrode manufacturers and researchers alike have endeavored to overcome reference electrode drift; focusing on improving the stability of the reference electrolyte to minimize ion mobility and exchange, improving the performance of the porous frit, or introducing junction systems. Solid-state reference electrodes (SSRE) have emerged as an alternative for $\mathrm{pH}$ insensitive electrodes due to the simplicity and ease of fabrication reducing the problems associated with conventional reference electrodes. However, they suffer drift when placed in complex media [11-13].

Pioneering work by Hickman et al. [14] demonstrated that conventional reference electrode limitations may be overcome by measuring the potential difference between the response of a $\mathrm{pH}$ sensitive and a $\mathrm{pH}$ insensitive (no proton transfer) redox compound. However, although such systems produce a $\mathrm{pH}$ insensitive signal, it is often found that the redox potential of the species is dependent on the concentration of ions in solution. A significant amount of focus has been on the use of ferrocene-based species, which experience a one electron oxidation to the resulting ferricenium ion $[15,16]$. Nevertheless, ferrocene has shown to suffer from electron mobility issues through the ferrocene chain, and the ferrocenium cation suffers from chloride-induced disproportionation [17]. This is therefore of no use for tracking reference potential voltage within systems containing unknown and changing concentrations of ions. The challenge, though, is to find a stable reference compound capable of being insensitive to varying concentrations of species found within the solution being tested.

Electrochemical system conditions are strongly dependent on the ionic strength of the solution [18]. M. Quan et al. [19] demonstrated the difference in redox behavior of quinones in buffered and unbuffered media, which is explained by the altered conditions in non-buffered media due to the voltammetry of redox species involving proton transfer. The electrochemical process involves consumption or release of protons at the surface of the electrode, perturbating the local $\mathrm{pH}$ of the solution, thus causing erroneous behavior. A simulation model presented by Compton et al. [20] shows that in some conditions the $\mathrm{pH}$ at the electrode surface can be altered up to 5-6 $\mathrm{pH}$ units comparing with that of the bulk solution. Compton noted that redox active species control the environment local $\mathrm{pH}$ of an electrode, but the difficulty of measuring the $\mathrm{pH}$ in that low buffered systems persisted. With the aim of monitoring the local $\mathrm{pH}$ in low ionic strength media, Dai et al. [21] presented a solution by manipulating the structure of the compounds on the electrode surface and proposed modified anthraquinone structures which facilitate proton transfer between the water molecules and the redox active moiety [22].

Lawrence et al. [23] utilized this local environment control to produce a new reference system in which the electrochemical process provided control of the $\mathrm{pH}$ in the environment local to the surface of the electrode. It has been seen that surface functional groups fundamentally affect adsorption characteristics of the material and so electrochemical performance [24].

This work presents a novel salicylic acid-based solid-state electrode for use as a stable voltametric reference. Salicylic acid (SA) presents a dissociation constant $\left(\mathrm{pK}_{\mathrm{a}}\right)$ of 2.97 and can be electropolymerized to obtain an electrochemical signal dependent on the $\mathrm{pH}$ of the system [25]. However, through impregnation of salicylic acid into a carbon epoxy electrode followed by subsequent electropolymerization, it is found that the acid moiety effectively sets the $\mathrm{pH}$, at the $\mathrm{pK}_{\mathrm{a}}$ value, in the vicinity local to the electrode. This paper demonstrates the versatility of this reference electrode through different medias, from high 
viscosity food-media to low buffer and low conductivity conditions, to high buffer and bio-based environment. Furthermore, Nafion ${ }^{\circledR}$ coated, electropolymerized, $\mathrm{pH}$ sensitive $2^{\prime}$-Hydroxyflavanone-based polymer is presented as a pH sensor [26], whereby Nafion ${ }^{\circledR}$ is used as a proton-exchange membrane to encourage the proton transfer between the media and the electropolymerized polymer.

This voltametric $\mathrm{pH}$ sensor is demonstrated in semi-solid food medias, such as soy sauce and raspberry syrup, in a hydroponic nutrient solution (Hoagland), sea water, and high buffered cell-culture media (DMEM), as well as standard buffer solutions. Hoagland solution provides every essential nutrient required by green plants and is appropriate for supporting growth of a large variety of plant species [27].

\section{Experimental}

\subsection{Apparatus}

Electrochemical measurements were conducted using an Ana Pot potentiostat (Zimmer \& Peacock, Coventry, UK) with a standard three-electrode configuration. A flavanone and salicylic acid-based carbon composite electrode were used as the working electrodes, a carbon counter and an $\mathrm{Ag} / \mathrm{AgCl}$ (BASi, West Lafayette, IN, USA) or a silver wire acted as the reference electrode.

Absolute $\mathrm{pH}$ measurements were performed using a standard glass electrode (Sensorex, Garden Grove, CA, USA). Prior to the measurement of the medias, the $\mathrm{pH}$ meter was calibrated using Reagecon buffers of $\mathrm{pH} 4.01 \pm 0.01, \mathrm{pH} 7.00 \pm 0.01$ and $\mathrm{pH} 10.01 \pm 0.01$ (Reagecon Diagnostics Ltd., Shannon, Ireland). Measurement of the $\mathrm{pH}$ was carried out on each freshly made solution prior to experiments. All the experiments were carried out at $20 \pm 1{ }^{\circ} \mathrm{C}$.

\subsection{Reagents}

All chemicals were purchased from Sigma-Aldrich, Dorset, UK, and used without further purification (unless specified). Standard IUPAC buffer solutions $(\mathrm{pH} 4,7,9)$ were prepared as follows: $\mathrm{pH} 4.07$-potassium hydrogen phthalate $(0.05 \mathrm{M})$; $\mathrm{pH}$ 6.86-potassium dihydrogen phosphate $(0.025 \mathrm{M})$ and sodium phosphate dibasic $(0.025 \mathrm{M}) ; \mathrm{pH} 9.23-$ sodium tetraborate $(0.05 \mathrm{M})$, all in deionized water (Hexeal, Brundall, UK). All buffers contained $0.1 \mathrm{M} \mathrm{KCl}$ as the supporting electrolyte.

Britton-Robinson buffer was used for the electropolymerization of salicylic acid (SA) carbon-based electrode, which consists of a mixture of $0.04 \mathrm{M}$ boric acid, $0.04 \mathrm{M}$ phosphoric acid and $0.04 \mathrm{M}$ acetic acid.

Raspberry syrup and soy sauce were purchased from local groceries and used as food-media testing. For the $\mathrm{pH}$ calibrations, different concentrations of $0.5 \mathrm{M} \mathrm{NaOH}$ stock solution were added into the semi-solid food medias, and the corresponding $\mathrm{pH}$ was measured using the standard glass electrode.

Hoagland's No. 2 Basal Salt Mixture was dissolved in $1 \mathrm{~L}$ deionized water and used as a hydroponic nutrient solution. Hoagland was diluted to 1:20, leading to a very low conductive solution. $\mathrm{NaOH} 0.5 \mathrm{M}$ and $\mathrm{HCl} 0.5 \mathrm{M}$ stock solution were used for adjusting the required $\mathrm{pH}$.

Sea water, H2Ocean Natural Reef Salt, was purchased from Maidenhead Aquatics (St. Albans, UK) in which $1 \mathrm{~kg}$ of this salt was dissolved in $25 \mathrm{~L}$ of water. For the seawater calibrations, different concentrations of $\mathrm{CO}_{2}$ were bubbled into a stirred sea water solution, and the corresponding $\mathrm{pH}$ measured using the standard glass electrode.

Dulbecco's Modified Eagle's Medium (DMEM) was used as a high buffered biomedia (purchased from Sigma Aldrich, Dorset, UK). Each powder bottle (around $8.5 \mathrm{~g}$ ) was dissolved in $1 \mathrm{~L}$ deionized water, and $3.7 \mathrm{~g} / \mathrm{L}$ sodium bicarbonate and $0.0159 \mathrm{~g} / \mathrm{L}$ phenol red was added to the solution in order to match the commercial composition of the bio-media. 


\subsection{Preparation of Carbon Composite Electrodes}

The flavanone-based carbon composite electrodes comprised of multi-walled carbon nanotubes, 2'-Hydroxyflavanone, Nafion ${ }^{\circledR}$ perfluorinated resin solution, with RX771C/HY1300 epoxy resin (purchased from Robnor ResinLab Ltd., Swindon, UK) used as the binder [26].

The salicylic acid-based carbon composite electrodes consist of $\mathrm{COOH}$-functionalized graphitized multi-walled carbon nanotubes (30-50 nm outside diameter, purchased from Cheap Tubes, Cambridgeport, VT, USA), glassy carbon (purchased from Sigma Aldrich, Dorset, UK), salicylic acid as redox active species, and RX771C/HY1300 epoxy resin (purchased from Robnor ResinLab Ltd., Swindon, UK) as the binder.

The preparation of both $\mathrm{pH}$ insensitive and $\mathrm{pH}$ sensitive electrodes is very similar. The carbon composite was first ground in a mortar until the powder was fine enough to mix homogeneously. The $\mathrm{pH}$ sensitive/insensitive species were then added and ground with the carbon in a known weight-to-weight ratio. In the case of the Nafion ${ }^{\circledR}$-coated electrodes, the flavanone compound was previously dissolved in Nafion ${ }^{\circledR}$. Both mixtures were dried at room temperature and were added to the carbon mix. Once the mixtures were homogeneous, they were carefully mixed with the epoxy resin, to form a carbon epoxy paste.

Each resulting mixtures were then packed into a recess ( $5 \mathrm{~mm}$ length, $1 \mathrm{~mm}$ diameter) of a PEEK ${ }^{\mathrm{TM}}$ manufactured body. Electrical connection was made using brass rod $(4 \mathrm{~cm}$ length, $1 \mathrm{~mm}$ diameter). The electrodes were cured at $125^{\circ} \mathrm{C}$ for $1 \mathrm{~h}$ to produce the solid carbon composite electrode.

\section{Results and Discussion}

Electropolymerization of salicylic acid (SA) carbon-based electrodes were first achieved using square wave voltammetry (SWV) in Britton-Robinson buffer, which is reflected in Figure 1a. This presents the first and thirtieth SWV of the reductive polymerization of a salicylic acid electrode. Scan 1 exhibited a reductive wave at $+0.755 \mathrm{~V}$, which increased in magnitude with increasing scan numbers. Furthermore, a shift in the potential to $+0.705 \mathrm{~V}$ was observed on scanning. This growth in peak current and shift in potential is consistent with the formation of a SA-based polymer on the electrode surface.

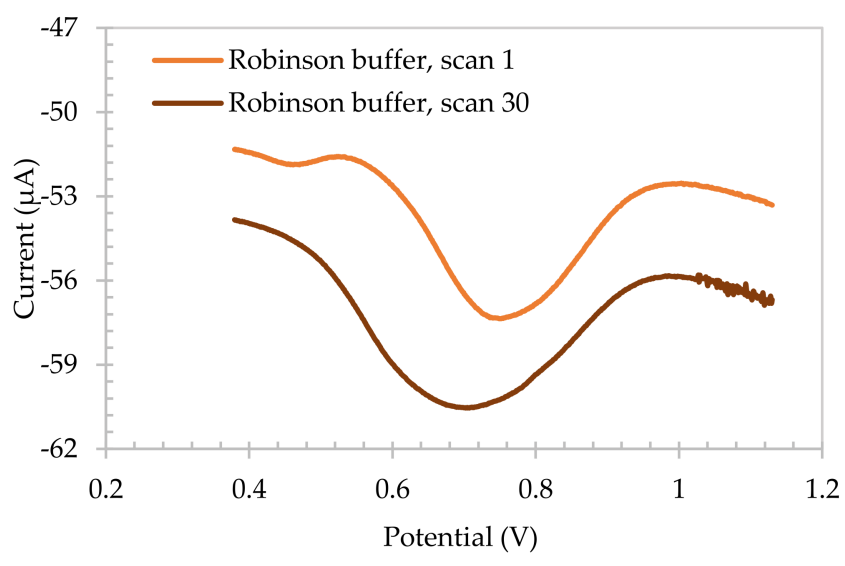

(a)

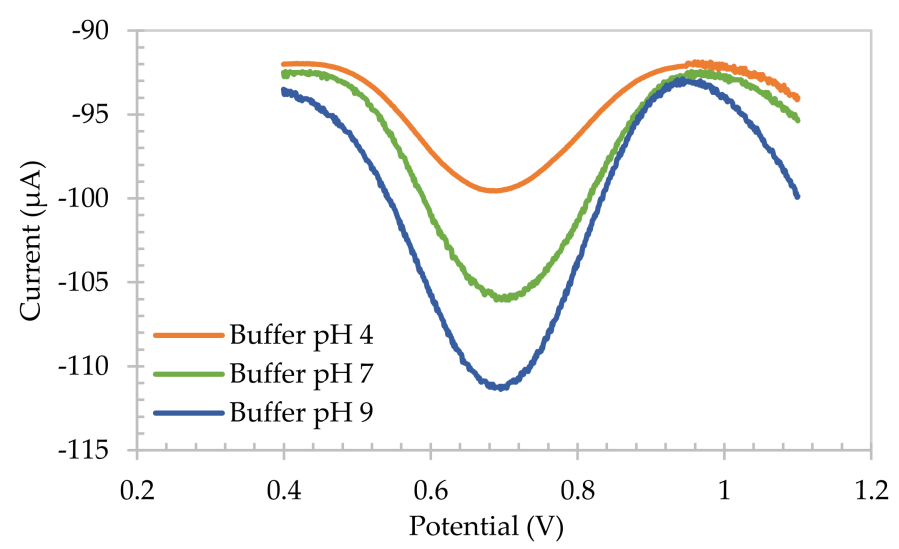

(b)

Figure 1. (a) Square Wave Voltammetry of scan 1 and scan 30 of reductive electropolymerization of salicylic acid carbon-based electrode when placed in $\mathrm{pH} 2$ Britton-Robinson buffer. (b) The resulting electropolymerized layer when placed in $\mathrm{pH} 4$, pH 7 and $\mathrm{pH} 9$ IUPAC standard buffers.

This result is consistent with the literature data which shows that oxidation of the SA monomer in acidic conditions produces a polymeric species on the electrode surface. Although the SA oxidation products have not been clearly identified, it is believed the oxidation is similar to that of phenol, as demonstrated by Park et al. [28] (Scheme 1). In this process it is shown that long chains of electropolymerized SA are difficult to obtain, 
rather the electrode is coated with short chained polymeric species. Indeed Scheme 1 shows the formation of three different radicals, forming some dimers after propagation, with a further oxidation of SA products. However, some trimers may also be formed during electropolymerization as well. Park et al. suggested that the electrochemical oxidation of SA can be impacted by intermolecular H-bonds formed by the carboxyl group, and intramolecular $\mathrm{H}$-bonds with the closest phenolic functional group, $\mathrm{C}=\mathrm{O} \cdots \mathrm{HO}$. The electrochemical reaction of the electrode when submerged in a solution is based on the hydrogen bonding formed by the hydrogen of the acid group, forming carboxylate anions on the surface of the electrode. The carboxylate anion is stabilized by intramolecular hydrogen bonding with the adjacent phenolic group [29].

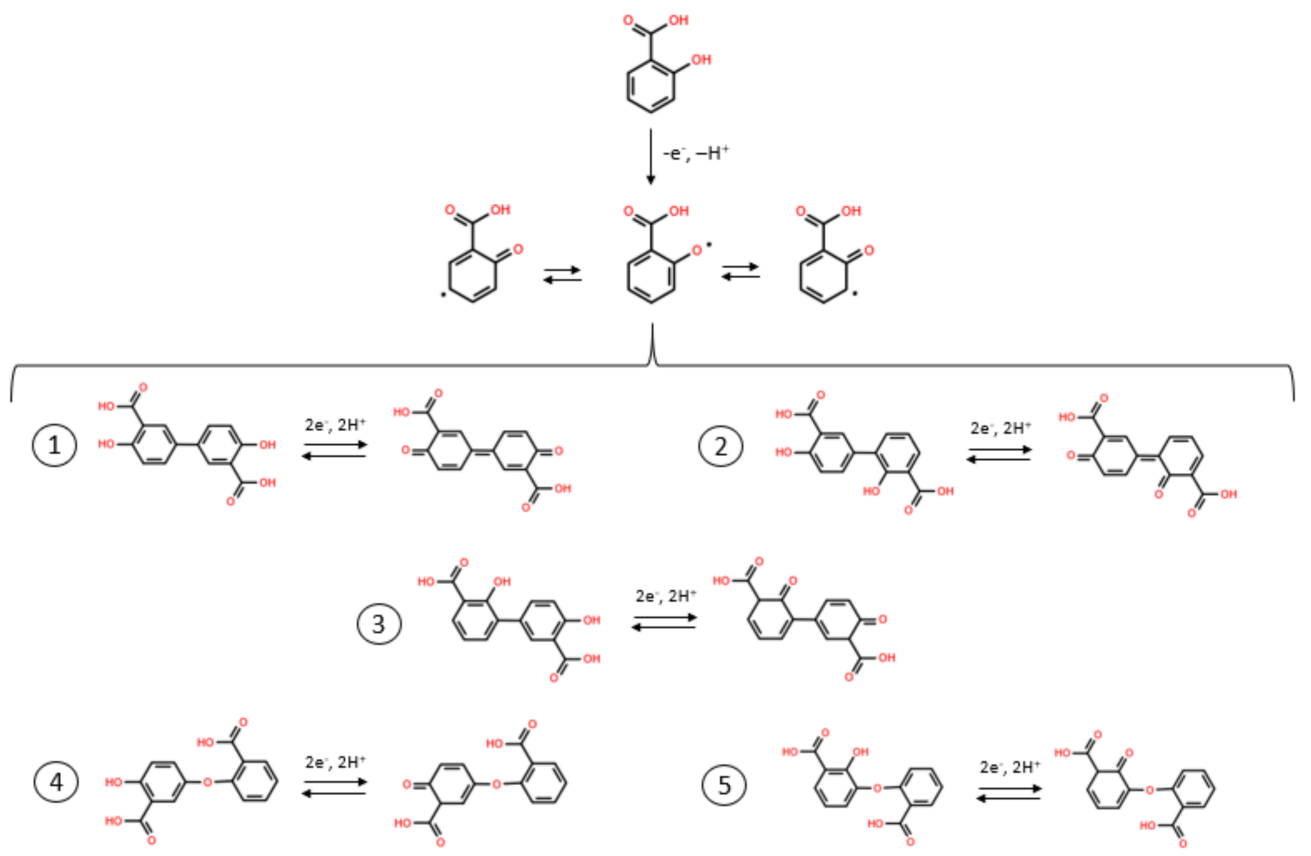

Scheme 1. Electrochemical oxidation pathways of salicylic acid.

Once polymerized, the SA electrode was removed from the $\mathrm{pH} 2$ polymerization solution and placed in IUPAC buffers, and the voltammetric response was analyzed. These data are shown in Figure 1b. Unlike the previous literature data [30], the peak potential of the redox active wave was found to be insensitive to the $\mathrm{pH}$ of the solution. This change in behavior was acquired by increasing the concentration of SA moieties in the surface of the electrode, and thus, increasing the ability of the chemistry to control the local pH. Knowing that the $\mathrm{pK}_{\mathrm{a}}$ of salicylic acid is 2.97 , it is assumed that the peak potential observed for the electrode in buffered media corresponds to $\mathrm{pH} 4$, consistent with the $\mathrm{pH}$ at the surface of the electrode. This is accordant with a high concentration of the SA being present on the electrode surface and setting the environment locale to the electrode by SA acidic moieties. This phenomenon allows the possibility of such an electrode to be used as a voltammetric reference electrode within certain low buffered media similar to that found in a number of food stuffs.

In order to study the versatility of salicylic acid electrodes, SWV were performed in different solutions: food-medias (raspberry syrup and soy sauce), Hoagland solution, synthetic seawater, and Dulbecco's Modified Eagle's Medium (DMEM). On one hand, raspberry syrup, soy sauce and Hoagland solution were used to demonstrate the ability of salicylic acid electrode as a reference system in the food industry. Raspberry syrup and soy sauce were interesting to the authors especially due to the rheological properties they possess, and the current issues the glass $\mathrm{pH}$ meter presents in these high viscosity medias. Hoagland is a hydroponic solution which provides every nutrient necessary for 
plant growth, and supports the growth of many plants. This solution was diluted in 1:20, in order to get a very low conductive solution (around $2 \mathrm{mS} / \mathrm{cm}$ ). On the other hand, salicylic acid-based electrode was also tested in synthetic seawater and DMEM bio-media, in order to show the adaptability of the $\mathrm{pH}$ insensitive sensor in different conditions, such as high salinity or different buffer concentrations, or even in a cell-culture media.

SA electrode was first tested in both raspberry syrup and soy sauce, which had a measured $\mathrm{pH} 3.18$ and 3.60, respectively, using a standard glass electrode. It can be foreseen that in a real-world application the SA electrode may not be polymerized prior to being tested so initial tests focused on understanding if the electropolymerization of SA would occur in this media. The electrode was first abraded to ensure a fresh, unpolymerized SA surface was present. The electrode was then immersed in soy sauce and 30 repetitive square wave voltammograms were recorded. Figure $2 \mathrm{a}$ shows the first and thirtieth voltammetric responses of the electrode. It can be clearly seen that the result is analogous to that shown in Figure 1a, with well-defined voltammetric responses observed and a stable peak potential from $+0.701 \mathrm{~V}$ to $+0.695 \mathrm{~V}$ over the thirty scans. This indicates the SA polymer can be easily formed in this media.

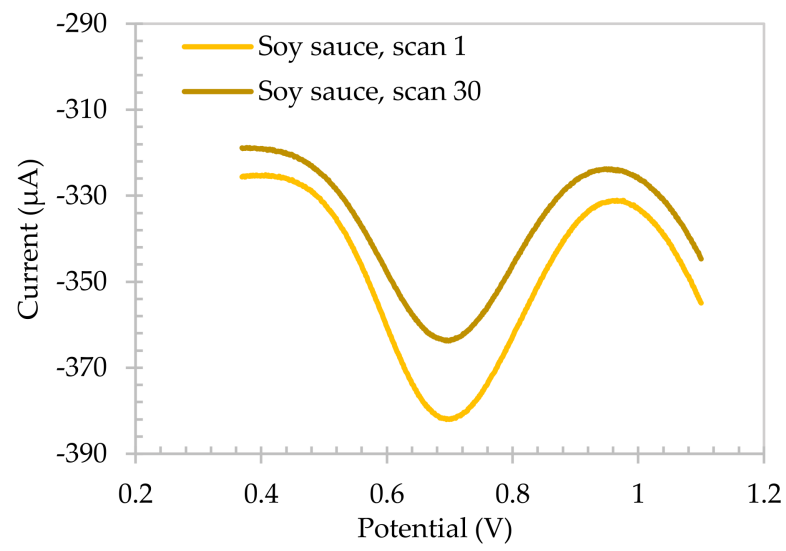

(a)

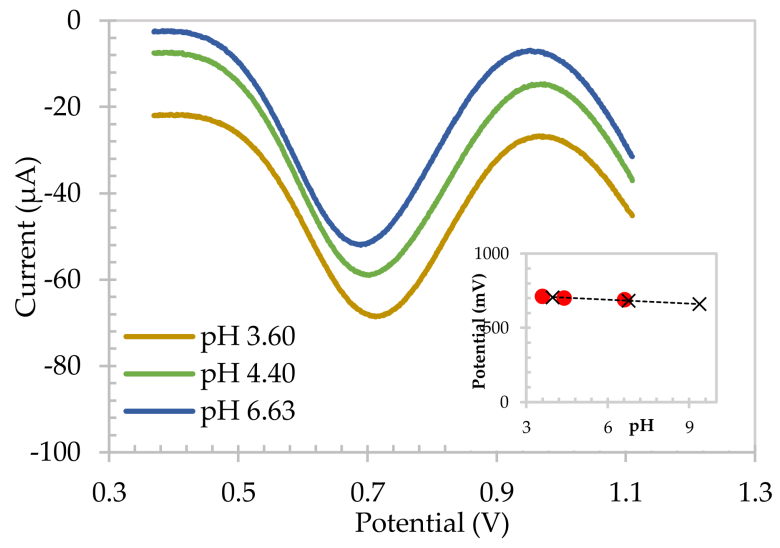

(b)

Figure 2. Square wave voltammograms for (a) scan 1 and scan 30 of SA electrode electropolymerized in soy sauce. (b) SA electrodes in soy sauce over different $\mathrm{pH}$ values, and calibration plot obtained in soy sauce and IUPAC standard buffers inserted.

To ensure the SA electrode exhibited $\mathrm{pH}$ insensitivity, and hence could be used as a reference electrode in this high viscosity media, $0.5 \mathrm{M} \mathrm{NaOH}$ aliquots were added to the soy sauce. The resulting voltammograms are shown in Figure $2 b$, confirming the stability of the peak potential over different $\mathrm{pH}$ values. Figure $2 \mathrm{~b}$ insert shows the resulting plot of the peak potential as a function of $\mathrm{pH}$ for soy sauce and $\mathrm{pH} 4, \mathrm{pH} 7$ and $\mathrm{pH} 9$ standard buffers. This shows a sensitivity of $-8.72 \mathrm{mV} / \mathrm{pH}$ unit for standard buffers, presented by the black trendline, and a sensitivity of $-7.47 \mathrm{mV} / \mathrm{pH}$ unit for soy sauce. This is in contrast with the previous literature data [30] and confirms that by increasing the concentration of the SA at the surface, the sensitivity of the SA electrodes is close to zero due to the carboxylic acid functionalities setting the local $\mathrm{pH}$ of the electrode to its $\mathrm{pK}_{\mathrm{a}}$.

The SA electrode was then tested in 1:20 diluted Hoagland solution. It was first abraded, removing the polymer formed on the surface of the electrode. SA was then polymerized directly in Hoagland solution ( $\mathrm{pH}$ 7.17). The $\mathrm{pH}$ was then adjusted by adding $0.5 \mathrm{M} \mathrm{NaOH}$ and $0.5 \mathrm{M} \mathrm{HCl}$ stock solution additions providing a $\mathrm{pH}$ range from 3.07 to 9.30. Well defined square wave voltammograms were obtained, as shown in Figure 3a in all solutions. The resulting plot of peak potential as a function of $\mathrm{pH}$ for the SAbased electrodes in diluted Hoagland solution overlayed the ones for raspberry syrup, soy sauce and IUPAC standard buffers, as detailed in Figure $3 \mathrm{~b}$. The sensitivity obtained for Hoagland solution was $-2.44 \mathrm{mV} / \mathrm{pH}$ unit, confirming the ability of the electrode to 
control the $\mathrm{pH}$ local to the electrode surface. These data thereby confirm the purpose of using SA-based carbon electrodes as a reference electrode in high viscosity food media as well as in hydroponic solutions with very low conductivity. The average peak potential of the SA electrodes in a range of $\mathrm{pH} 2.83-9.30$ for both medias was $701.9 \pm 7.2 \mathrm{mV}$.

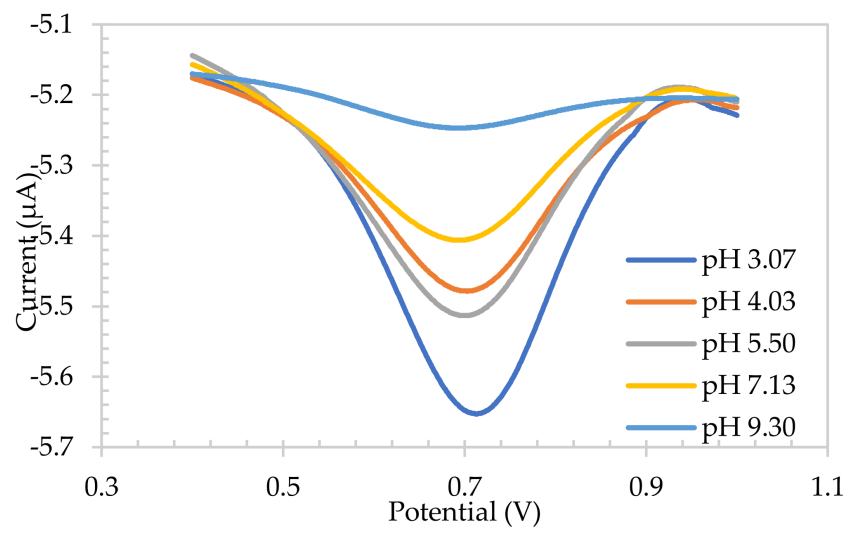

(a)

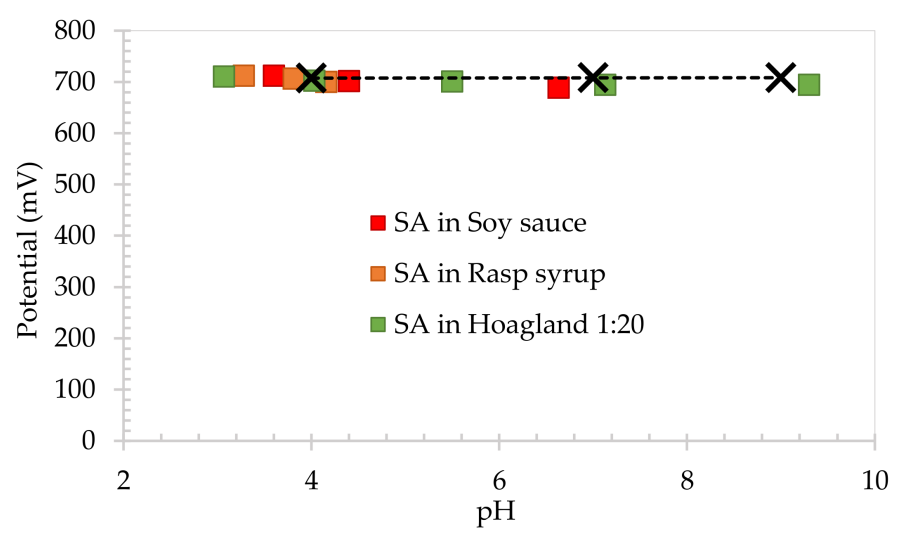

(b)

Figure 3. (a) Square wave voltammograms of salicylic acid electrodes in diluted Hoagland solution, and (b) calibration plot for SA-based electrodes in raspberry syrup, soy sauce, Hoagland and pH 4, pH 7 and $\mathrm{pH} 9$ IUPAC standard buffers.

In order to prove the adaptability of the SA electrode as a $\mathrm{pH}$ insensitive sensor in different conditions, the electrode was tested in synthetic sea water, and in DMEM high buffered bio-based solution. In this case, the electrode was abraded again to ensure a fresh, unpolymerized SA surface, and electropolymerized in Britton-Robinson for 30 scans (not shown) prior to each test. Once polymerized, SA electrode was tested in sea water, with additions of different $\mathrm{CO}_{2}$ concentrations for adjusting the required $\mathrm{pH}$. The $\mathrm{pH}$ measured by the glass $\mathrm{pH}$ probe ranged 8.20 to 6.51 . Additions of $\mathrm{NaOH} 0.5 \mathrm{M}$ and $\mathrm{HCl} 0.5 \mathrm{M}$ stock solutions were added to DMEM to adjust the $\mathrm{pH}$ across the range from $\mathrm{pH} 6.66$ to $\mathrm{pH} 9.42$. The results obtained for the calibration plot of SA electrodes in seawater $/ \mathrm{CO}_{2}$ system and DMEM solutions overlayed the previous food media and hydroponic solutions, with an average peak potential of $+709.2 \pm 0.4 \mathrm{mV}$ and $+699.3 \pm 6.4 \mathrm{mV}$, subsequently, as shown in Figure 4. The sensitivities exhibited in these two medias were $-0.25 \mathrm{mV} / \mathrm{pH}$ unit for seawater and $+2.50 \mathrm{mV} / \mathrm{pH}$ unit for DMEM. Sensitivity being very close to zero confirms the purpose of using salicylic acid carbon-based electrode as a reference electrode in low buffered systems, indicating the ability of the chemistry to control the environmental local $\mathrm{pH}$ of the electrode surface, due to the acid concentration of the surface.

It has been seen that salicylic acid-based carbon electrode can be used as a reference electrode, since the electrode is able to control the local $\mathrm{pH}$ without perturbating, leading to a stable peak potential over all the solutions used, without regarding the composition, ionic strength, or conductivity.

With the aim of using SA electrode as a reference system, the electrochemical response of the flavanone-based $\mathrm{pH}$ sensing electrodes was then tested using square wave voltammetry in the same medias, and the calibration plot obtained is also presented in Figure 4, showing a $\mathrm{pH}$ sensitive behavior. The flavanone electrode was first electropolymerized in the food media as outlined previously [19]. In this case a reductive wave was observed at $+0.465 \mathrm{~V}$ for scan 1 which was shifted to $+0.440 \mathrm{~V}$ on consecutive scans and stabilized after 5 scans (not shown). As with SA electrodes, $\mathrm{pH}$ was adjusted in each solution to study the behavior of the electrode for different $\mathrm{pH}$ in each media. Figure 5 presents the redox waves for each solution. It can be clearly observed that the peak potential shifts to lower potentials as the $\mathrm{pH}$ of the solution increases. Black trendline in Figure 4 (circles) shows the buffer calibration of Flavanone electrodes, with a sensitivity of $-55.7 \mathrm{mV} / \mathrm{pH}$. A linear 
plot of peak potential with $\mathrm{pH}$ was observed in all the different conditions, overlaying the buffer calibration trendline with a sensitivity of $-46.2 \mathrm{mV} / \mathrm{pH},-53.6 \mathrm{mV} / \mathrm{pH}$ unit, $-54.8 \mathrm{mV} / \mathrm{pH}$ unit and $-55.8 \mathrm{mV} / \mathrm{pH}$ unit for food media, Hoagland hydroponic solution, seawater $/ \mathrm{CO}_{2}$ system and DMEM bio-based media, respectively. The resulting polymer was found to provide a Nernstian response in high/low buffered, low conductivity, high viscosity, and cell-culture medias.

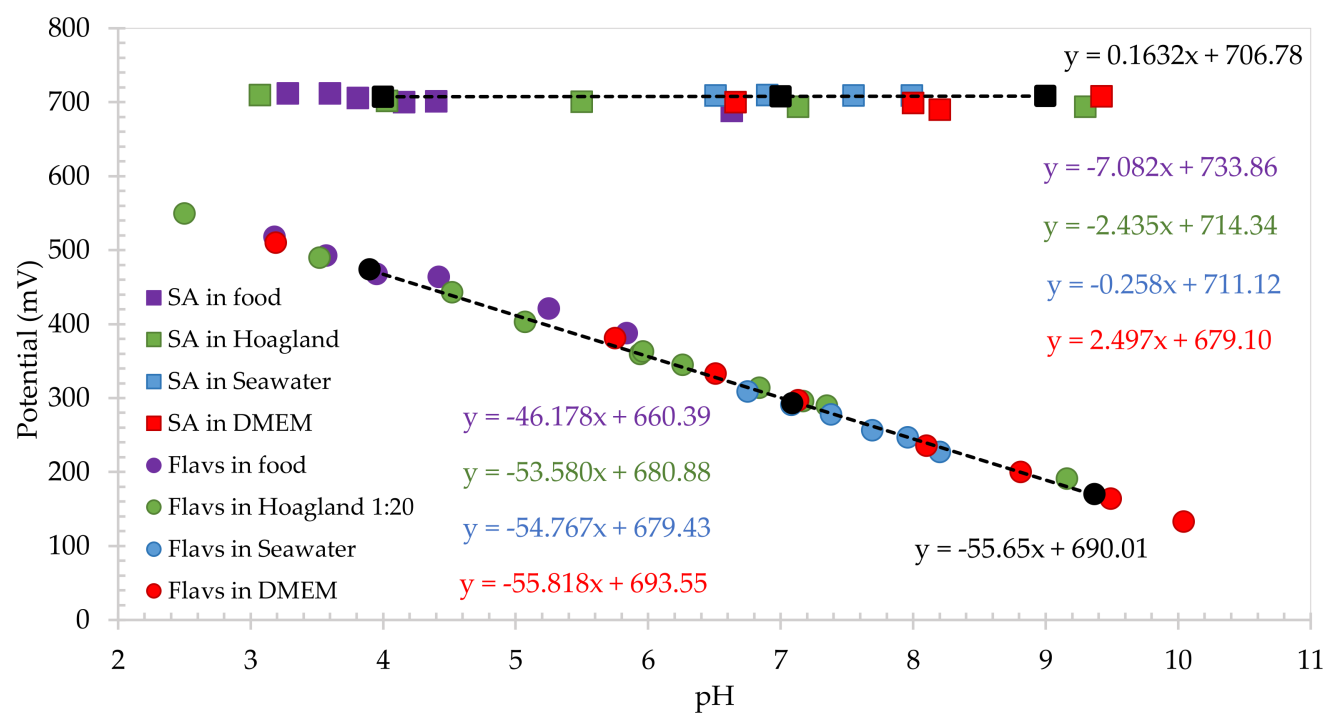

Figure 4. Calibration plot of salicylic acid-based $\mathrm{pH}$ insensitive (squares) and flavanone-based $\mathrm{pH}$ sensitive electrodes (circles) in different food medias, Hoagland diluted hydroponic solution, seawater $/ \mathrm{CO}_{2}$ system and DMEM solution.

Figure 6 shows the results when this flavanone-based $\mathrm{pH}$ sensing electrode is combined with the SA-based carbon reference electrode. Subtracted values were calculated using the calibration trendline of SA electrodes over the flavanone's calibration line. As expected, peak potentials obtained in all the different solutions follow the same trendline as the IUPAC buffers calibration, meaning that the SA reference electrode is controlling the $\mathrm{pH}$ of the local environment, regardless of the composition, ionic strength, conductivity, or rheological properties of the environment.

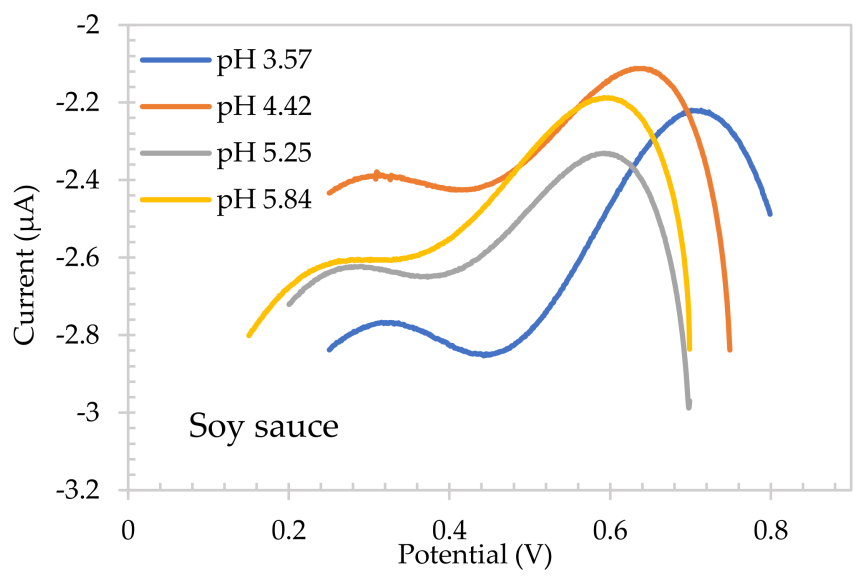

(a)

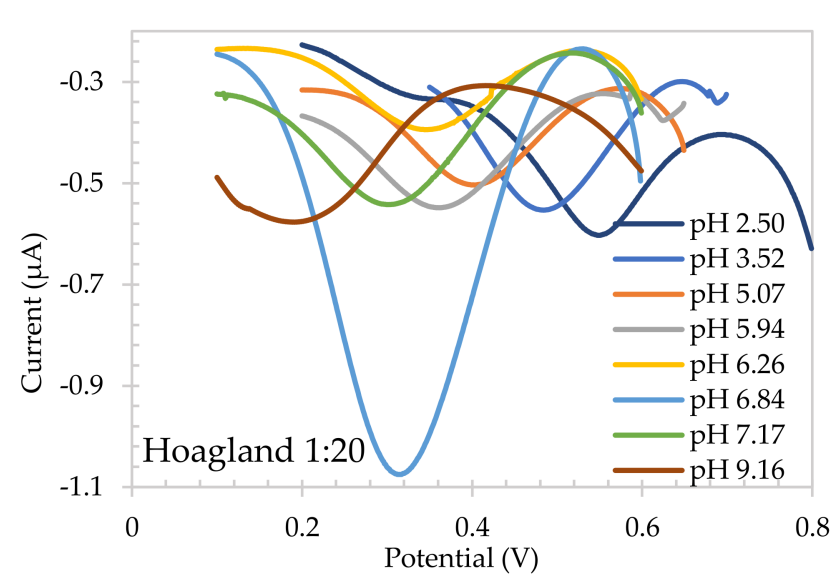

(b)

Figure 5. Cont. 


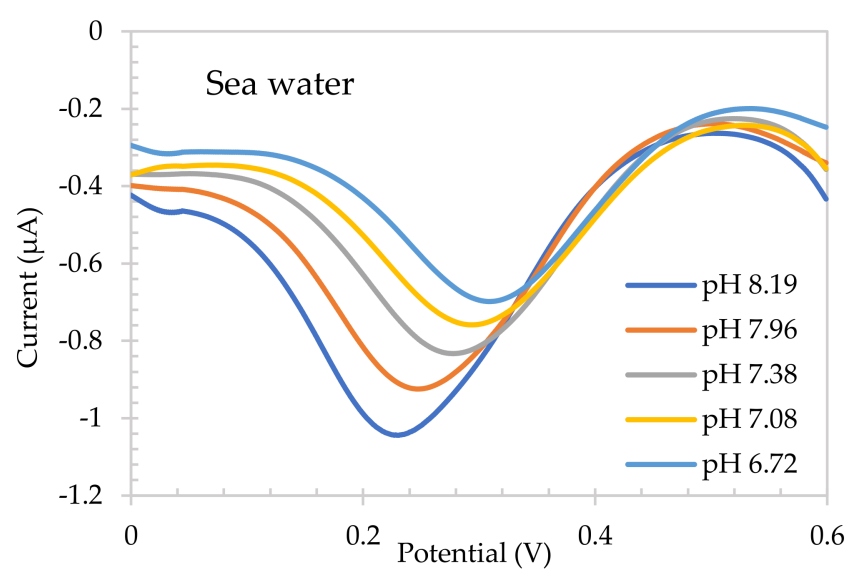

(c)

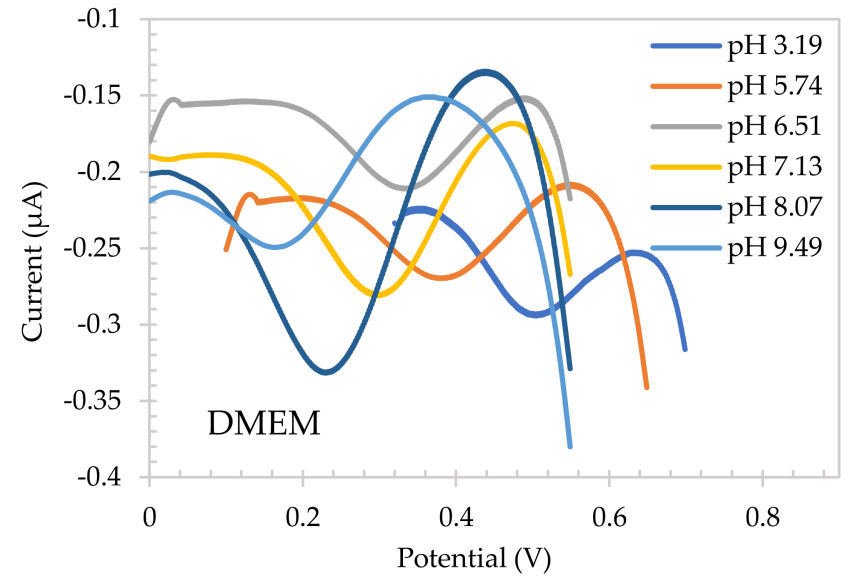

(d)

Figure 5. Square wave voltammograms for Flavanone-based electrodes in $\mathrm{pH}$ adjusted (a) soy sauce, (b) 1:20 diluted Hoagland solution, (c) sea water, and (d) DMEM.

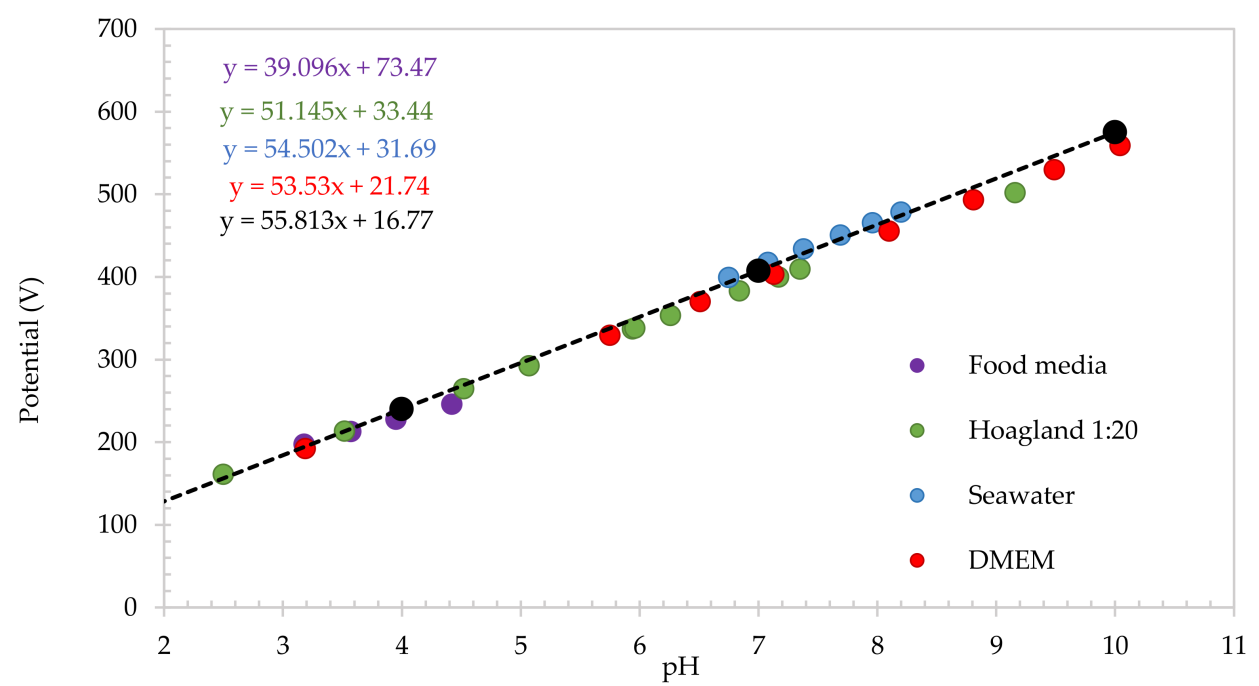

Figure 6. Calibration of electrodes based on subtracted values ( $\triangle$ SA-Flav) in different medias and IUPAC standard buffers.

Table 1 summarizes the data obtained from each calibration plot, excluding IUPAC buffers. The $\mathrm{pH}$ was accurately calculated in all the solutions, demonstrating the ability of a flavanone/SA voltammetric-based sensor to monitor $\mathrm{pH}$ medias well known to be troublesome for the traditional glass electrode such as high viscosity solution, low buffered, low ionic strength, hydroponics, and cell-culture media.

Table 1. Data obtained from the calibration plots of both salicylic acid and flavanone-based electrodes in raspberry syrup and soy sauce. Comparison of the glass electrode measured $\mathrm{pH}$ and calculated one based on the calibration equation is presented for each solution. Subtracted data are shown as well.

\begin{tabular}{cccc}
\hline & \multicolumn{3}{c}{ Subtracted $\boldsymbol{\Delta}_{\text {ref-pH }}$} \\
\hline & Calibration Equation & Measured $\mathbf{p H}$ & Calculated $\mathbf{p H}$ \\
\hline Raspberry syrup & $\mathrm{y}=39.10 \mathrm{x}+73.5$ & 3.18 & 3.13 \\
Soy sauce & $\mathrm{y}=39.10 \mathrm{x}+73.5$ & 3.60 & 3.67 \\
1:20 Hoagland & $\mathrm{y}=51.15 \mathrm{x}+33.4$ & 7.17 & 7.13 \\
Sea water & $\mathrm{y}=54.50 \mathrm{x}+31.7$ & 8.20 & 8.25 \\
DMEM & $\mathrm{y}=53.53 \mathrm{x}+21.7$ & 8.10 & 8.08 \\
\hline
\end{tabular}


Finally, to demonstrate the efficacy of SA pH insensitive sensor as a long-term $\mathrm{pH}$ sensor, experiments in soy sauce and diluted Hoagland solution were carried out. The two environments were chosen specifically as one exhibits high viscosity (soy sauce) and the other is a low conductivity and low buffer solution (diluted Hoagland hydroponic solution), both of which are very interesting to the author.

Figure 7 shows the SWV of SA electrode every 20 tests (which corresponds to 60 scans) in soy sauce. The electrodes were immersed and scanned every half an hour over 10 days, with a total of 260 measurements. They showed a slight decay in signal over the first three sets, and an increased in stability thereafter. After 10 days of testing, the electrode still showed a very defined SWV, verifying its long lifetime capabilities and long-lasting accuracy in high viscosity media.

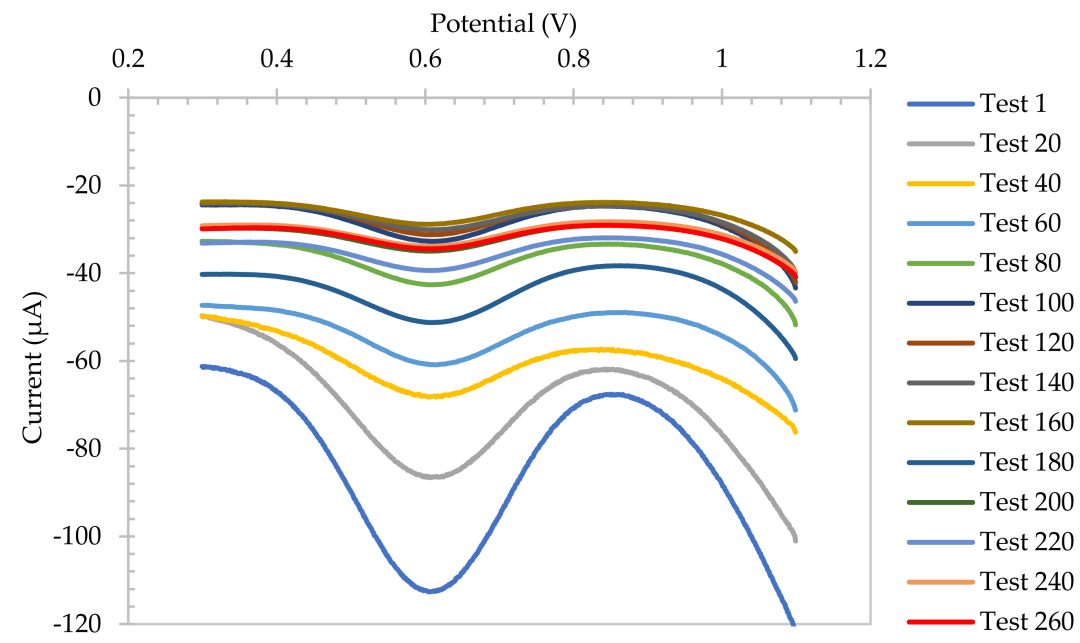

Figure 7. Square wave voltammograms of SA electrode every 20 tests, scanned every half an hour over 10 days, with a total of 260 tests.

Long term experiments in Hoagland 1:20 diluted were also carried out. SA electrode was first abraded to ensure an unpolymerized surface and polymerized in Britton-Robinson solution. It was then stored in Hoagland x20 solution over a week, in order to study the influence of the solution in the calibration plot. The storage condition did not affect the chemistry of the electrode, as Figure 8 presents. A sensitivity of $0.18 \mathrm{mV} / \mathrm{pH}$ unit as recorded after day 5 with the calibration plot overlaying that obtained on day 1 . The SA electrode was immersed and scanned every hour over 37 days, with a total of 5000 scans showing the long-term stability of the electrode in these media.

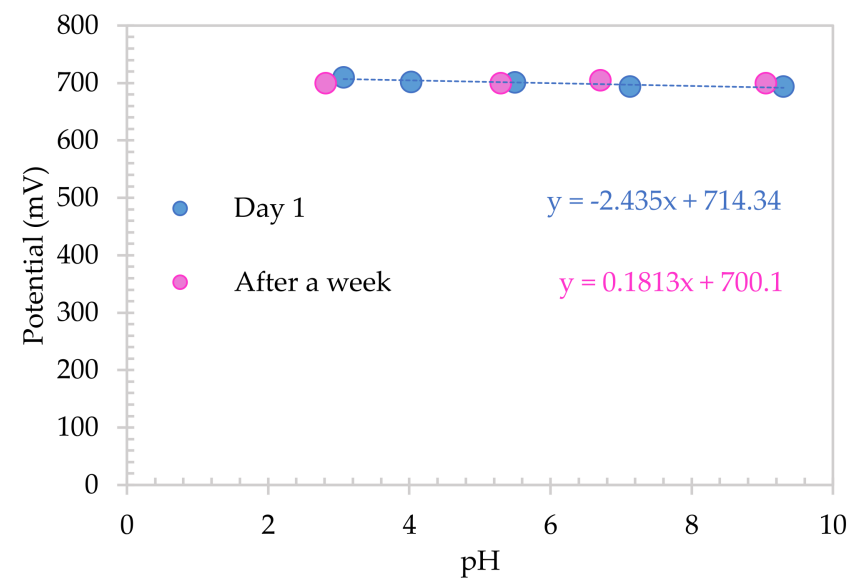

Figure 8. Calibration plot for SA electrode in diluted Hoagland solution for day 1 and after being stored in solution over a week. 
This successfully long-term data confirmed the ability of salicylic acid moiety to behave as a reference electrode for low buffer systems, showing very stable potentials over a long period of time, making it suitable for deployment with no calibration needed.

\section{Conclusions}

A novel solid-state reference electrode utilizing salicylic acid carbon composite-based electrodes has been successfully developed, which overcome the issues of standard reference electrodes. The resulting polymer was found to provide an insensitive response in high viscosity food media, low conductivity and low buffer hydroponic solution, sea water, and high buffered cell-culture media, presenting sensitivities of $-7.1 \mathrm{mV} / \mathrm{pH}$ unit, $-2.4 \mathrm{mV} / \mathrm{pH}$ unit, $-0.2 \mathrm{mV} / \mathrm{pH}$ unit, and $2.5 \mathrm{mV} / \mathrm{pH}$ units, respectively, and thus, indicating the ability to control the $\mathrm{pH}$ of the local environment around the electrode surface, due to the acid concentration on the surface. SA reference electrodes were successfully tested in solutions with different compositions, ionic strengths, and conductivities.

Flavanone-based $\mathrm{pH}$ electrodes were successfully tested in all the solutions used for SA measurements, providing a Nernstian response by combining with the SA reference electrode, demonstrating that the SA electrode can be efficiently used as a reference system. The calculated $\mathrm{pH}$ values were in excellent agreement for each solution, showing a maximum error of $+/-0.03 \mathrm{pH}$ unit, based on the equation obtained from the calibration plots and the measured $\mathrm{pH}$ using a calibrated glass electrode.

The efficacy of SA pH insensitive sensor as a long-term reference for a $\mathrm{pH}$ sensor was demonstrated in soy sauce and diluted Hoagland solution. After 10 days of testing in soy sauce, the electrode still showed a very defined SWV with no drift in potential, verifying its long lifetime capabilities and long-lasting accuracy in high viscosity media. It was also demonstrated that the sensor could be stored in Hoagland solution (1:20) for over a week without adverse effect. A sensitivity of $0.18 \mathrm{mV} / \mathrm{pH}$ unit was shown after a week, with the calibration plot overlaying that obtained on day $1(-2.4 \mathrm{mV} / \mathrm{pH}$ unit). The SA electrode was immersed and scanned every hour over 37 days, with a total of 5000 scans confirming the long-term stability in these media.

Author Contributions: Conceptualization; M.M.M., K.L.M. and N.S.L.; methodology, M.M.M., K.L.M. and N.S.L.; validation, M.M.M., K.L.M. and N.S.L. All authors have read and agreed to the published version of the manuscript.

Funding: This project has received funding from the European Union's Horizon 2020 research and innovation program under grant agreement No 82297, and Innovate UK grant funding, Grant no. 133171.

Institutional Review Board Statement: Not applicable.

Informed Consent Statement: Not applicable.

Data Availability Statement: Not applicable.

Acknowledgments: ANB Sensors gratefully acknowledges funding this work through Innovate UK grant funding and European Union's Horizon 2020 research and innovation program. Innovate UK is the UK's innovation agency. It works with people, companies, and partner organizations to find and drive the science and technology innovations that will grow the UK-economy.

Conflicts of Interest: The authors declare no conflict of interest.

\section{References}

1. Choi, I.; Lee, J.Y.; Lacroix, M.; Han, J. Intelligent $\mathrm{pH}$ indicator film composed of agar/potato starch and anthocyanin extracts from purple sweet potato. Food Chem. 2017, 218, 122-128. [CrossRef]

2. Srbinovska, M.; Gavrovski, C.; Dimcev, V.; Krkoleva, A.; Borozan, V. Environmental parameters monitoring in precision agriculture using wireless sensor networks. J. Clean. Prod. 2015, 88, 297-307. [CrossRef]

3. Si, Y.; Grazon, C.; Clavier, G.; Rieger, J.; Audibert, J.F.; Sclavi, B.; Méallet-Renault, R. Rapid and accurate detection of Escherichia coli growth by fluorescent $\mathrm{pH}$-sensitive organic nanoparticles for high-throughput screening applications. Biosens. Bioelectron. 2016, 75, 320-327. [CrossRef] [PubMed] 
4. Priya, S.K.; Shenbagalakshmi, G.; Revathi, T. Design of smart sensors for real time drinking water quality monitoring and contamination detection in water distributed mains. Int. J. Eng. Technol. 2018, 7, 47-51. [CrossRef]

5. Takeshita, Y.; Martz, T.R.; Johnson, K.S.; Dickson, A.G. Characterization of an Ion Sensitive Field Effect Transistor and Chloride Ion Selective Electrodes for $\mathrm{pH}$ Measurements in Seawater. Anal. Chem. 2014, 86, 11189-11195. [CrossRef] [PubMed]

6. The Importance of $\mathrm{pH}$ Measurement in Assuring Product Quality. Available online: https://www.manufacturing.net/home/ article/13183102/the-importance-of-ph-measurement-in-assuring-product-quality (accessed on 10 November 2021).

7. Barron, F.H.; Fraser, A.M. Acidified Foods: Food Safety Considerations for Food Processors. In Food Industry; Muzzalupo, I., Ed.; Department of Food, Nutrition and Packaging Sciences, Clemson University: Clemson, SC, USA, 2013; pp. $232-239$.

8. Graham, D.J.; Jaselskis, B.; Moore, C.E. Development of the Glass Electrode and the pH Response. J. Chem. Educ. 2013, 90, 345-351. [CrossRef]

9. Skoog, D.A.; West, D.M.; Holler, J.F.; Crouch, S.R. Fundamentals of Analytical Chemistry, 8th ed.; Thomson-Brooks/Cole: Belmont, CA, USA, 2004; ISBN 9780495558286.

10. Kampouris, D.K.; Kadara, R.O.; Jenkinson, N.; Banks, C.E. Screen printed electrochemical platforms for pH sensing. Anal. Methods 2009, 1, 25-28. [CrossRef] [PubMed]

11. Lewenstam, A.; Blaz, T.; Migdalski, J. All-Solid-State Reference Electrode with Heterogeneous Membrane. Anal. Chem. 2017, 89, 1068-1072. [CrossRef]

12. Noh, J.; Park, S.; Boo, H.; Kim, H.C.; Chung, T.D. Nanoporous platinum solid-state reference electrode with layer-by-layer polyelectrolyte junction for pH sensing chip. Lab Chip 2011, 11, 664-671. [CrossRef]

13. Karthick, S.; Lee, H.S.; Lee, Y.S.; Singh, J.K.; Kwon, S.J.; Natarajan, R. Fabrication of a Cerium-doped nickel ferrite solid-state reference electrode and its performance evaluation in concrete environment. Sens. Actuators B Chem. 2017, 251, 509-523.

14. Hickman, J.J.; Ofer, D.; Laibinis, P.E.; Whitesides, G.M.; Wrighton, M.S. Molecular Self-Assembly of Two-Terminal, Voltammetric Microsensors with Internal References. Science 1991, 252, 688-691. [CrossRef] [PubMed]

15. Devlin, L.; Jamal, M.; Razeeb, K.M. Novel pH sensor based on anthraquinone-ferrocene modified free standing gold nanowire array electrode. Anal. Methods 2013, 5, 880-884. [CrossRef]

16. Lafitte, V.G.H.; Wang, W.; Yashina, A.S.; Lawrence, N.L. Anthraquinone-ferrocene film electrodes: Utility in pH and oxygen sensing. Electrochem. Commun. 2008, 10, 1831-1834. [CrossRef]

17. Wright, K.J.; Oiaidha, Z.O.; Love, D.P.; Aljohani, M.; Greenway, G.M.; Wadhawan, J.D. Imaging immunoassay in negative: Surface catalysed chemiluminescence for the detection of pregnancy hormones in artificial saliva. New J. Chem. 2018, 42, 18641-19648. [CrossRef]

18. Salgin, S.; Salgin, U.; Bahadir, S. Zeta Potentials and Isoelectric Points of Biomolecules: The Effects of Ion Types and Ionic Strengths. Int. J. Electrochem. Sci. 2012, 7, 12404-12414.

19. Quan, M.; Sanchez, D.; Wasylkiw, M.F.; Smith, D.K. Voltammetry of Quinones in Unbuffered Aqueous Solution: Reassessing the Roles of Proton Transfer and Hydrogen Bonding in the Aqueous Electrochemistry of Quinones. J. Am. Chem. Soc. 2007, 129, 12847-12856. [CrossRef]

20. Batchelor-McAuley, C.; Kozub, B.R.; Menshykau, D.; Compton, R.G. Voltammetric Responses of Surface-Bound and SolutionPhase Anthraquinone Moieties in the Presence of Unbuffered Aqueous Media. J. Phys. Chem. 2011, 115, 714-718. [CrossRef]

21. Dai, C.; Chan, C.W.I.; Barrow, W.; Smith, A.; Song, P.; Potier, F.; Wadhawan, J.D.; Fisher, A.C.; Lawrence, N.S. A Route to Unbuffered pH Monitoring: A Novel Electrochemical Approach. Electrochim. Acta 2016, 190, 879-886. [CrossRef]

22. Dai, C.; Song, P.; Wadhawan, J.D.; Fisher, A.C.; Lawrence, N.S. Screen Printed Alizarin-Based Carbon Electrodes: Monitoring pH in Unbuffered Media. Electroanalysis 2015, 27, 917-923. [CrossRef]

23. Lawrence, N.S. Reference Electrode Using Local Environment pH Control. US Patent 0,293,592, 26 September 2019.

24. Hemmatifar, A.; Oyarzun, D.I.; Palko, J.W.; Hawks, S.A.; Stadermann, M.; Santiago, J.G. Equilibria model for pH variations and ion adsorption in capacitive deionization electrodes. Water Res. 2017, 122, 387-397. [CrossRef]

25. Yang, X.; Kirsch, J.; Fergus, J.; Simonian, A. Modeling analysis of electrode fouling during electrolysis of phenolic compounds. Electrochim. Acta 2013, 94, 259-268. [CrossRef]

26. Miranda, M.; Carvetta, C.; Sisodia, N.; Shirley, L.; McGuinness, K.L.; Wadhawan, J.D.; Lawrence, N.S. Nafion ${ }^{\circledR}$ Coated Electropolymerised Flavanone Based pH Sensors. Electroanalysis 2021. submitted. [CrossRef]

27. Smith, G.S.; Johnston, C.M.; Cornforth, I.S. Comparison of nutrient solutions for growth of plants in sand culture. New Phytol. 1983, 94, 537-548. [CrossRef]

28. Park, J.; Eun, C. Electrochemical Behavior and Determination of Salicylic Acid at Carbon-fiber Electrodes. Electrochim. Acta 2016, 194, 346-356. [CrossRef]

29. Stradins, J.; Hasanli, B. Anodic voltammetry of phenol and benzenethiol derivatives: Part 1. Influence of pH on electro-oxidation potentials of substituted phenols and evaluation of pKa from anodic voltammetry data. J. Electroanal. Chem. 1993, 353, 57-69. [CrossRef]

30. Dai, C.; Crawford, L.P.; Song, P.; Fisher, A.C.; Lawrence, N.S. A novel sensor based on electropolymerized substituted-phenols for $\mathrm{pH}$ detection in unbuffered systems. RSC Adv. 2015, 5, 104048. [CrossRef] 